\title{
Building employability skills for higher education students: An Australian example
}

\author{
Robert Gill ${ }^{1}$ \\ rgill@swin.edu.au \\ ${ }^{1}$ Swinburne University of Technology
}

\begin{abstract}
Employability has become an important focus for graduates and employers in Australia, as many universities contend with the notion of developing knowledgeable and problem-solving graduates who are workforce ready practitioners. This paper presents an example of how the higher education communication disciplines from across Victoria, Australia, have developed a forum that allows graduating students to engage directly with industry leaders to better prepare for the leap from higher education to professional employment in the communication and media sectors. This national award-winning education forum brings multi-institutional student groups, recent graduates, academics, and industry practitioners and leaders together in order to aid the development of student skills in areas such as: networking, job application, time management, and effective work habits.
\end{abstract}

Keywords: employability, graduate attributes, student forum

\section{Introduction}

This paper explores the example of the Public Relations, Media and Communication (PRMC) Student Forum. The forum is an avenue for both industry and academia to identify and address gaps in the higher education and tertiary curriculum. This is achieved through a multiinstitutional workshop that enhances learning experiences for graduate attributes and employability. The forum and its teaching pedagogy is moulded by industry feedback, student feedback and academic observations. The content is weighted to higher education students due to the nature of the delegate list. The unique value in the development of this learning and teaching tool is that the content and curriculum have evolved over eight years, involving collaboration and feedback between educators, students and industry.

\section{Being work-ready}

Employability skills and conceptions on how to make such skills more prominent in the curriculum have been a strong focus in Australian higher education for the past 20 years (Moore \& Morton, 2017). Over the past two decades, there has been an increased focus on practical skills, both nationally and internationally, through a movement towards making them more noticeable and explicit in the higher education curriculum. Ruth Bridgstock (2009), a prominent academic writing in the employability space, stated that shifts in education and labour market policy have resulted in universities being placed under increased pressure to produce employable graduates, with less focus on philosophical and higher-order thinking skills.

Many terms are used to describe practical and 'work-ready' skills, including generic skills, essential skills, soft skills, key competencies, transferable skills, enterprise skills and 21 st 
century skills. The frameworks that include these skills are also broader than those just relevant to employment and may include capabilities that can be described as life skills or graduate attributes (Yorke, 2004; Bridgstock, 2009). The value is in the non-technical knowledge, skills and attributes required that enable employees to effectively participate in the workforce (Cranmer, 2006).

In Victoria, Australia, an unusual collaboration has been formed between competing universities to develop an annual one-day student workshop open to all graduating students in the communication and media disciplines. The PRMC Student Forum brings together Victorian students from across these disciplines. Students network with industry leaders, exchange opinions and ideas with their peers, are coached in preparing for the workforce, visit operating workplaces, and freely mix with practitioners and recently employed graduates with the main objective of being better prepared for the transition from study to professional employment. The forum helps students identify those areas in their skill set that contribute to making them more employable. The experiences from the forum aid in developing generic graduate attributes and employability skills, or at least enable students to identify those attributes they will need to advance in order to become more proficient in the professional communication environment. This forum was awarded an Australian Learning and Teaching Citation in $\mathbf{2 0 1 6}$ for its contribution to building employability skills, and is the case discussed below.

\section{Defining graduate attributes and employability}

Generic graduate attributes can be described as being the skills, personal attributes and values, which are intended to be acquired by graduates regardless of their discipline or field of study (Smith \& Bath, 2006). Bowden (in Bridgstock, 2009) refers to the definition that graduate attributes are the qualities, skills and understandings a university community agrees its students would desirably develop during their time at the institution. Smith and Bath (2006) state these attributes or outcomes typically include a combination of qualities such as: critical thinking, intellectual curiosity, problem-solving, logical and independent thought, communication and information management skills, intellectual rigour, creativity and imagination, ethical practice, integrity and tolerance.

Employability can be defined as a set of achievements - skills, understandings and personal attributes - that make graduates more likely to gain employment and be successful in their chosen occupations, benefiting themselves, the workforce, the community and the economy (Yorke, 2004). Cranmer (2006) suggests such employability skills need to be incorporated into teaching and learning experiences in order to enhance graduates' ability to secure jobs. The amount of development and nurtured skills making graduates ready for work in the curriculum is defined as the level of graduate employability, according Boden and Nedeva (2010).

Employers increasingly want graduates with job skills such as communication, teamwork and problem-solving (Innovative Research Universities, 2011). According to many theorists, these attributes or employability qualities, identified as soft skills or intangible assets, are often difficult to authentically replicate in a fabricated classroom environment (for example: Moore \& Morton, 2017; Smith \& Bath, 2006; Wibrow, 2011; Andrews and Higson, 2008). Soft skills are considered those abilities to create working relationships and practical work habits that aid in efficient production. The 2013 commissioned report by the Australian Federal Department of Education, Employment and Workplace Relations identified such graduate skills as missing, yet essential, part of the students' toolkit to transition from study to employment (Commonwealth of Australia, 2013).

The introduction and development of the PRMC Student Forum discussed in this case aims to address what employability (soft) skills are needed to better prepare graduating students for the higher-level demands of professional communication roles. The forum embeds graduating students in real working environments and connects them with high-level practitioners. This is done specifically to advance the development of these soft or intangible skills that frame graduate attributes. 


\section{Higher education and practical skills}

Higher education in Australia is considered to provide an education rather than being a training base (Bowen \& Schwartz, 2010). This educational philosophy subsists to enable graduates to develop the higher order thinking that equips them to produce value from knowledge they have internalised through their study (Walker, 2006). Many theorists believe the core function of higher education is to provide an environment where students can utilise their body of knowledge to evolve into successful problem-solvers and logical persuaders, based on a capacity to think logically and critically (Wheelahan \& Moodie, 2011; Phillips, 2005; Bowen \& Schwartz, 2010). This distinction is based on the ancient Plato philosophy regarding training the brain to search for truth, whereas Aristotle's philosophy centred on practical skills and the search for the rational approach (Korthagen \& Kessels, 1999).

However, as indicated, the professional industry is looking for graduates who come equipped with the skills to be begin their employment confident and capable in task-orientated operations, as Aristotle proposes. In other words, graduates who have a set of skills that define them as work-ready (Bridgstock, 2009). This work-ready approach supports the notion of teaching that limits its practice to the intellectual level of academic competence and favours the practical and operational competence of the work environment (Light, Cox \& Calkins 2009). Therefore, the Plato model resonates with higher education, focuses on teaching episteme which can be characterised as abstract, objective and propositional knowledge, whereas an Aristotle model focuses on teaching phronesis which is perceptual knowledge gained through practical wisdom based on the perception of a situation (and Korthagen \& Kessels, 1999).

The position for the industry is that graduates need to be competent with task-oriented responsibilities and abilities to function in a professional work environment, but such skills are currently lacking (Moore \& Morton, 2017). The forum has been initiated to help address some of these employability skills gaps.

\section{PRMC student forum background}

In 2010 the Swinburne University of Technology (Swinburne) communication discipline initiated an academic forum for Victorian public relations (PR) academics to meet and discuss areas in PR higher education that may be in need of advancement. A common issue raised by many institutions related to the anxiety students experienced moving from study to work, due to limited opportunities to directly engage with industry management and to exercise decision-making in authentic working environments. This was also flagged as a common concern for many graduating students (Andrews \& Higson, 2008). Deakin, Victoria and Swinburne Universities formed a research committee as a result of the issues raised at the academic forum and agreed to develop an annual Communication Student Forum that targeted some of the identified gaps between current curriculum, which typically struggles to address employability skills and progressive innovation towards transition into professional work at an institutional level. As discussed by the academics at the initial forum, these gaps in employability skills related to practical workplace skills developed in situ by practitioners embedded in the workplace.

The committee invited contributions from industry and other tertiary institutions regarding the objectives, content and delivery of the forum over 2010 and 2011. The PRMC Student Forum was developed to help students address some of the identified gaps in graduate attributes, and was first held in 2011.

The basic structure for the forum involves an annual theme with relevant and prominent key speakers, industry case studies highlighting excellence in practice, a question and answer session with recently employed graduates, a roundtable with recruitment professionals, visits to operating workplaces, and an informal networking event with industry and academics. The morning sessions involve keynote speakers with expertise in the chosen theme. Themes todate have included: crisis communication, social media, emerging technology, celebrity and 
fashion publicity, and media management. The middle sessions have included example case studies, application processes and question sessions with recently graduated students. The afternoon sessions have involved visits to operating businesses and agencies. The evening sessions have provided feedback and networking in a social environment.

Communication and Media students from across Victoria are invited to attend the forum, but the emphasis and content has been more relevant to students nearing the end of their studies. The forum is open to both undergraduate and postgraduate students. Student online networking sites are set-up to continue the evolving discussions post-forum. The format is an exemplar for similar forums to be set up across major Australian commercial centres, as was requested in 2015 by the Public Relations Institute of Australia's (PRIA) National Education Manager.

\section{Data collection and participation}

The data included in this paper is a result of exit surveys for both students and industry participants. The student delegate list is dominated by higher education undergraduate students, but also includes 12 per cent tertiary and nine per cent post-graduate contributors to survey responses. The industry contributions have been gathered from 33 senior industry presenters, 27 recent graduates and 26 different professional organisations in the Melbourne, Victoria area.

There are many reasons why students chose to attend the forum (see Figure 2), but significantly 80 per cent of attendees consider the forum improved their prospect of becoming employed in the industry (Exit and Feedback Surveys, 2011-17).

The forum has evolved and grown in student attendances (Figure 2) and industry contributions reflecting professional leadership and innovation in communication (Table 1) over the past seven years. The forum has drawn on the experience of more than 60 industry leaders, enhancing the curriculum by providing students with direct access to leadership and innovation expertise, not typically available to students in the classroom. Annual attendances are around 90 delegates, as the forum's popularity resulted in a registration cap due to engagement and functionality limitations.

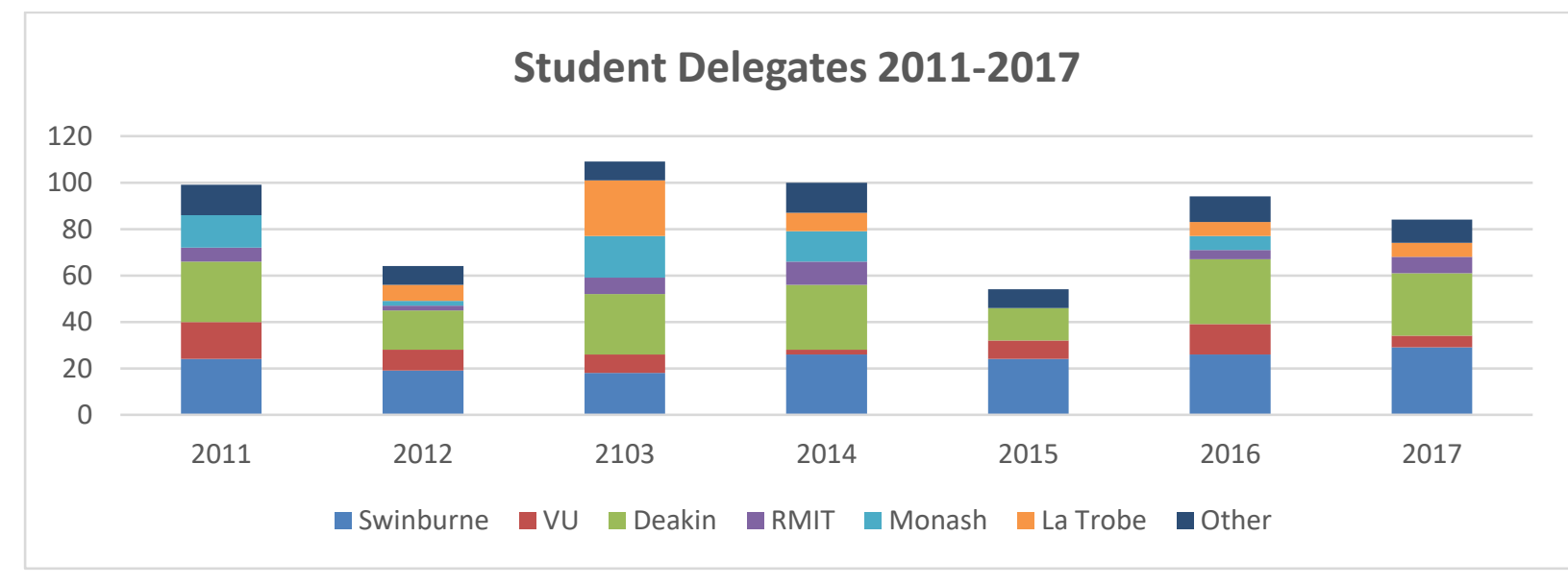

Figure 1: Forum Attendances

The forum has transferrable success from year-to-year because graduating students and the industry have this opportunity to come together and share knowledge relating to critical skills, challenges, and barriers to successful employment specific and current to the communication industry. 


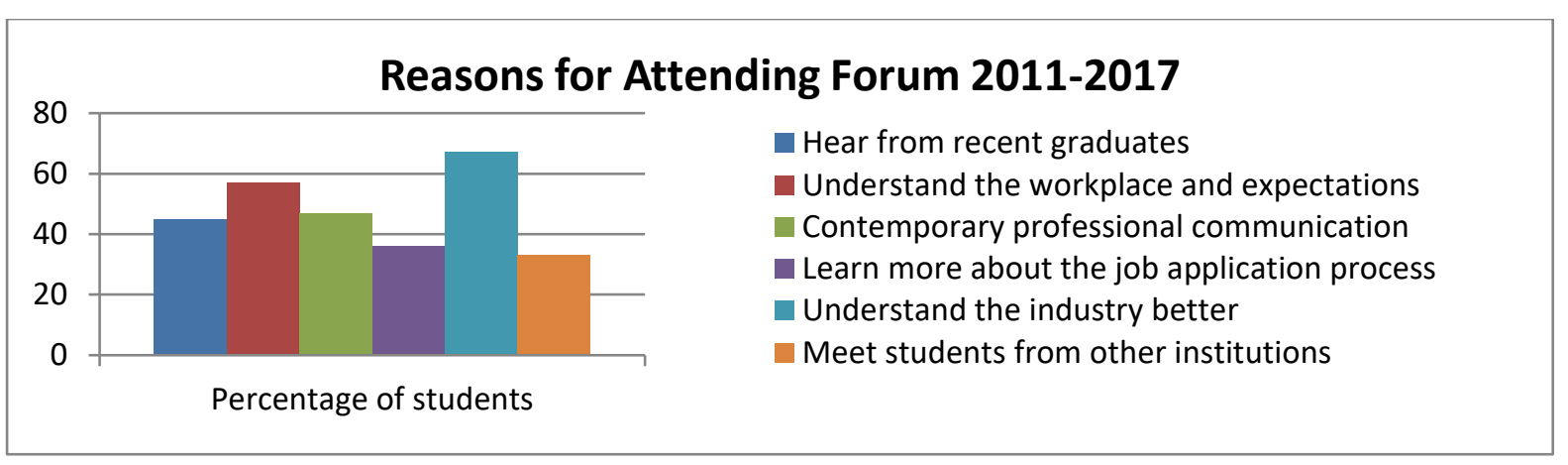

Figure 2. Reasons for Attending Forum

The forum has created exceptional learning and experiences for the vast majority of attending students, with 73 per cent of surveyed delegates stating it was "very beneficial" and a combined 90 per cent saying it made "considerable contributions" to their learning (Feedback Surveys, 2011-2017), matched against overall course satisfaction ratings for Higher Education in Victorian universities being 78 per cent (Uni. Review, 2015). Much of the students' feedback relates to the value in improving their employability skills, exposure to the industry work environment, networking opportunities with both employers and like-students, and the shared experiences with practitioners and recently employed graduates (see Figures 2, 3, \& 4).

\section{Influence on student learning, engagement and experience}

The structure of the forum (mentioned above) aims to better prepare graduating students in professional communication for the workforce by enhancing employability skills. To achieve this, the founding academic committee agreed on four basic aims for the forum:

1. Improving student employability and graduate attributes through deeper understandings of the diverse work environments and through providing actual (authentic) workplace experiences

2. Expanding students' networks in industry to enhance their professional profile

3. Refining each graduates' preparation of their curriculum vitae, interview techniques and electronic profiles

4. Creating cross-institution student hubs (both face-to-face and online) where students can share their concerns, anxieties and skills regarding moving into the professional workforce

These aims have been overwhelmingly achieved to date, as already highlighted, $90 \%$ of student feedback stating the forum made positive contributions to their learning; and $89 \%$ of industry feedback confirming students present for work as more employable due to the employability skills they can identify as needing further development, as a result of the forum. Industry feedback has suggested students come to graduate positions better prepared for the professional environment. Students are exposed to a variety of professionals to advance their employability skills (aim 1), with each industry representative sharing their own experience and understanding of professional communication and the desired skill sets. Student knowledge is further advanced through visiting workplaces and mixing with practitioners.

Annual forum themes have included: understanding sectors in professional communication; big business or agency roles; ethics in communication practice; the importance of social and mobile communication; and, being employment ready. Industry 'open houses' are where students register to attend up to two workplaces and directly experience the working environments, ask questions about roles and responsibilities, and gain a deeper understanding of the specifics for the particular business. 
Table 1. Industry Contributions

\begin{tabular}{|l|c|c|c|c|c|c|c|}
\hline $\begin{array}{l}\text { Industry } \\
\text { Contributors }\end{array}$ & $\begin{array}{l}\text { Media } \\
\text { Agency }\end{array}$ & Consultant & $\begin{array}{l}\text { Corporate } \\
\text { I Gov't. } \\
\text { Business }\end{array}$ & NGO & $\begin{array}{l}\text { Association } \\
\text { S }\end{array}$ & $\begin{array}{l}\text { Recent } \\
\text { Grad. }\end{array}$ \\
\hline $\begin{array}{l}\text { Speakers and } \\
\text { Presenters }\end{array}$ & 14 & 11 & 7 & 5 & 4 & 12 & 27 \\
\hline $\begin{array}{l}\text { Open House: } \\
\text { student visits }\end{array}$ & 13 & 15 & 6 & 7 & 3 & N/A & N/A \\
\hline
\end{tabular}

Deliberately, a diverse mix of workplaces are sourced each year to provide students opportunities to experience distinct work environments and better understand the employability skills particular to these roles (see Table 1). From feedback, 57 per cent stated they wanted to get a feel from employers about necessary skills for the workplace and 32 per cent wanting to see exactly how the workplace operates. And 45 per cent indicated they wanted to better understand workplaces and the expected skills needed to perform effectively.

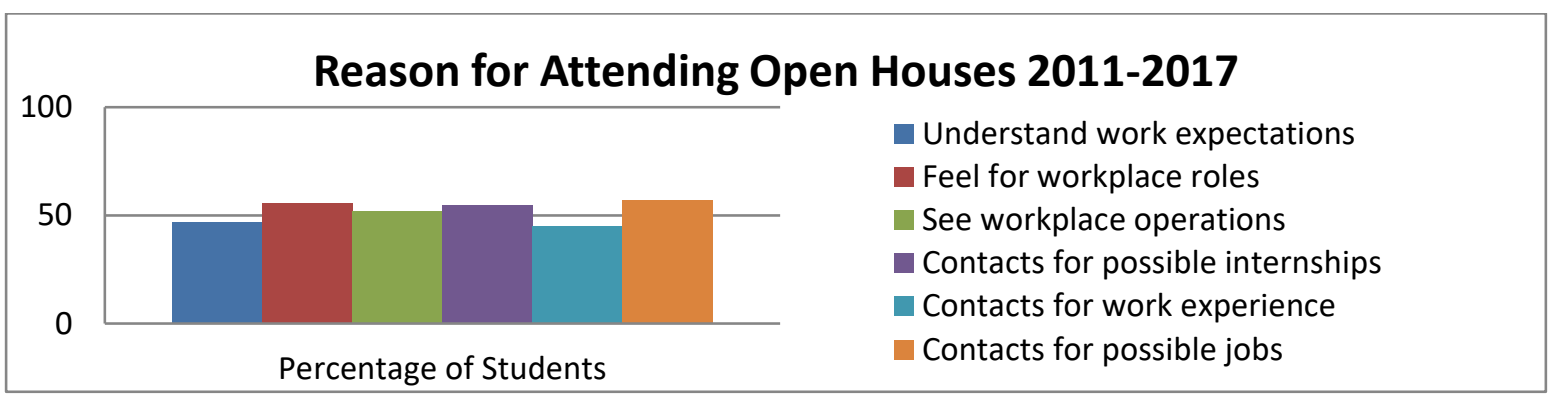

Figure 3. Student Feedback: Benefits to Attending Open Houses

Students expressed a need to heighten their profile (aim 2) with potential employers, with 55 per cent believing the open house experiences will improve their chance of getting an internship, and 58 per cent believing it will improve the possibility of getting a job. Visiting workplaces and meeting managers and directors also creates familiarity and raises that student's profile, with the intention to improve employment and Work Integrated Learning (WIL) placements for forum students through these businesses, as students can develop professional relationships with business managers and staff through these visits (see Figure 3).

Networking has been identified as key graduate attribute that is difficult to foster in the classroom environment (Bridgstock, 2009). The forum provides many opportunities for students to engage with and establish professional contacts within industry, and with students from other institutions. More than $50 \%$ of students stated in feedback they use the forum to directly network with industry management, and $54 \%$ indicated they will use networking to directly secure a job or an internship.

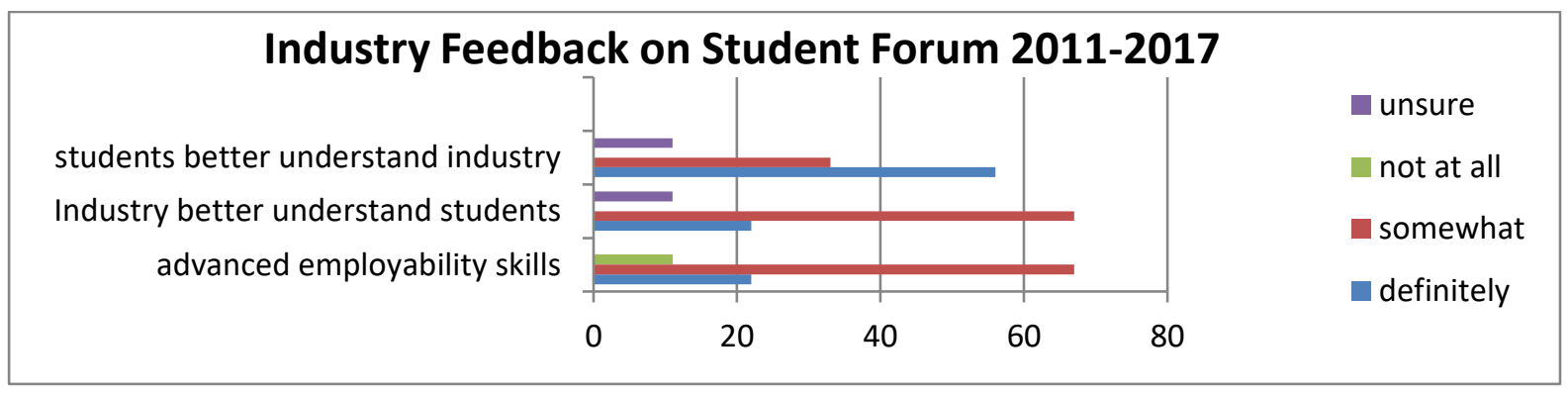

Figure 4. Industry Feedback: Student Forum Benefits

Gill, R. (2018). Building employability skills for higher education students: An Australian example. Journal of Teaching and Learning for Graduate Employability, 9(1), 84-92. 
As mentioned above, a key industry concern relates to students' employability skills, particularly interpersonal skills and professional presentation (objective 3). The forum agenda incorporates recent employed graduates who share their experiences and challenges with finding and moving into professional communication roles (27 graduates have presented at the forum to-date). These graduates remain for the duration of the forum and openly engage with interested students during breaks. Almost 20 per cent of the further comments section of feedback specifically indicated the employed graduate conversations were critical to their understanding of the industry. The informal atmosphere during breaks in the program mitigates barriers often associated with formal presentations and encourages students to share apprehensions and concerns they may not be comfortable airing in a public forum (Chaney \& Martin, 2011).

Many comments from student feedback related to being better prepared for the application and interview process, so in 2015, an innovative inclusion to the agenda was 'speed information' sessions. These sessions involved students forming into small groups (mixed across the institutions) and visiting work stations where an industry expert would interact for 15 minutes on topics such as: CV preparation, electronic profiles, interview techniques, choosing the right job, professional networking, and the use of WIL to help with employment. The feedback on this new session was exceptional, with 61 per cent of 2015 feedback sheets stating the speed sessions as being the most benefit to student learning, as students were able to share their own stories and hear the professional experiences of the facilitator and students from other institutions - opportunities typically not available at their institutions.

An intended consequence was the forming of student groups and students unofficially learning from each other (objective 4). Such student interaction across the institutions enables sharing of information around their fears, anxieties and the challenges of moving from higher education into the workforce. Students were encouraged to join social media network groups relating to the forum and to further develop these networks - and in many cases, new friendships - as often these students will be their industry colleagues in the near future. Students have created social media sites to continue their collegial networks, including: Facebook sites for yearly forums, instagram and Twitter tags. Also, the forum and has links to further discourse on employability with other students through the International PR Summit Student Forums. Formal forum platforms have included: priablog/student forum, themediapod.victorian_student_forum and pria.com.au/communications/student forum. At a more informal level, students have also created their own social media hubs (typically through Facebook) to continue the network and conversations beyond the forum. Around 35 per cent of students (see Figure 1) specifically stated the collegiality they establish with similar students from other institutions as a key motivation for coming to the forum.

There are limitations to the capacity of a one-day forum to significantly impact on the curriculum and learning for higher education students. However, the intention of the forum is enable students to gain further insight into the industry, develop working relationships with industry management, create student information hubs that facilitate further conversations (and build student networks), and help students identify those areas of employability they may not feel they have a strong foundation in. The aims of the forum are strongly linked to awareness, which can assist student pinpointing strategies for improvement that may make them more employable.

To date the forum has been recognised by industry and academia in several ways, including:

- $\quad 2016$ Australian National Learning and Teaching Citation Award

- $\quad$ High Commendation for student-industry engagement as part of the 2015 Swinburne University Vice Chancellor Awards.

- $\quad$ All six state-based universities offering communication degrees in Victoria have been represented on the Committee over the past 8 years, and enthusiastically 
encourage participation by their students (supported by strong attendance numbers across institutions, Figure 2).

- $\quad$ As indicated, industry feedback on student interactions demonstrates that 56 per cent state definitely and 33 per cent substantially that the forum has improved students' understanding of the industry and its demands.

\section{Summary}

The PRMC Student Forum is a simple example of how higher education and tertiary institutions in Australia can address some of the identified gaps in employability and graduate attribute skills for students leaving study and entering the professional communication workforce. In the past, many students have expressed apprehensions about moving into the workforce, and many professional organisations have expressed a desire to have more workready graduates. The forum data and feedback demonstrates that issues can be addressed by providing an opportunity for students and employers to discuss and identify how transition from study to work can be more effective and assured. Then build a network of opportunities and experiences, which can help alleviate student anxiety and build surety in expectations for students entering the professional communication workspace. The forum will continue to run for the eighth time in 2018. 


\section{References}

Andrews, J., \& Higson, H. (2008). Graduate employability, 'soft skills' versus 'hard' business knowledge. A European Study Special Issue: Employability, Mobility and the Labour Market, 33(4), 411-422.

Boden, R., \& Nedeva, M. (2010). Employing discourse: Universities and graduate 'employability'. Journal of Education Policy, 25(1), 37-54, DOI:10.1080/02680930903349489

Bowen, W.M., \& Schwartz, M. (2010). The chief purpose of universities: Academic discourse and the diversity of ideas. Cleveland: Urban Affairs Books.

Bridgstock, R. (2009). The graduate attributes we've overlooked: Enhancing graduate employability through career management skills. Higher Education Research \& Development, 28(1), 31-44.

Channey, L.H., \& Martin, J.S. (2011). Intercultural business communication (5 $5^{\text {th }}$ Edition). New Jersey: Pearson Education.

Commonwealth of Australia. (2013). Core skills for work developmental framework, A joint statement prepared by the Ithaca Group, on behalf of the Department of Industry, Innovation, Climate Change, Science, Research and Tertiary Education and Department of Education, Employment and Workplace Relations. Canberra: Australia.

Cranmer, S. (2006). Enhancing graduate employability. Studies in Higher Education, 31(2), $169-184$.

Department of Education and Training. (2016). Australian awards for university teaching. 2016 citations for outstanding contributions to student learning. Australia Government, Available at: https://docs.education.gov.au/node/41811

Korthagen, F. A. J., \& Kessels, J. P. A. M. (1999). Linking theory and practice: Changing the pedagogy of teacher education. Educational Researcher, 28(4), 4-17.

Light, G., Cox, R., \& Calkins, S. (2009). Learning and teaching in higher education - the reflective professional. London: Sage Publications.

Moore, T., \& Morton, J. (2017). The myth of job readiness? Written communication, employability, and the 'skills gap' in higher education. Studies in Higher Education, 42(3), 591-609.

Phillips, R. (2005). Challenging the primacy of lectures: The dissonance between theory and practice in university teaching. Journal of University Teaching and Learning Practice, 12(1), 1-3.

Smith, C., \& Bath, D. (2006). The role of the learning community in the development of discipline knowledge and generic graduate outcomes. Higher Education, 51(2), 259-86.

University Review (2015). Course satisfaction ratings by students. Available at: https://universityreviews.com.au/course-ratings-by-students/

Walker, M. (2006). Higher Education Pedagogies. New York: Open Universities Press.

Wheelahan, L., \& Moodie, G. (2011). Rethinking skills in vocational education and training: From competencies to capabilities. Sydney: NSW Board of Vocational Education and Training.

Wibrow, B. (2011). Employability Skills: at a glance. Department of Education, Employment and Workplace Relations. Available at: https://www.ncver.edu.au/_data/assets/file/0013/2407/2404.pdf

Yorke, M. (2004). Employability in Higher Education: what it is - what it is not. Higher Education Academy/ESECT. Available at http://www.employability.ed.ac.uk/What/index.htm 